\title{
Analysis of the Power Quality in Six-phase Induction Motor Drives with Arbitrary Winding Spatial Shifting
}

\author{
J.J. Aciego ${ }^{1}$, M.J. Duran ${ }^{1}$, I. Gonzalez-Prieto ${ }^{1}$ and F. Barrero ${ }^{2}$ \\ ${ }^{1}$ Department of Electrical Engineering \\ E.T.S.I.I., University of Málaga \\ e-mail: mjduran@uma.es \\ ${ }^{2}$ Department of Electronic Engineering \\ University pf Seville \\ e-mail: fbarrero@us.es
}

\begin{abstract}
Multiphase machines are becoming an alternative to the three-phase standard in high power applications with high reliability requirements. Due to the capability to inherit off-the-shelf three-phase technology, the most popular choice at industry is the use of multiple threephase windings. The disposition of the different sets of threephase winding is however varied. In the specific case of sixphase machine, a spatial shifting among the three-phase windings of $0^{\circ}, 30^{\circ}$ and $60^{\circ}$ has been used in dual-three-phase, asymmetrical and symmetrical machines, respectively. This spatial displacement has an impact on the power quality of the currents that supply the machine since the same magnetomotive force (MMF) in the airgap can be generated with different harmonic cancellation between phases. This work considers an arbitrary spatial shifting of the threephase windings in order to explore its impact on the power quality from the machine-side. Extensive simulation results compared the different types of six-phase machine and some conclusions are extracted about the advantages of each choice.
\end{abstract}

Key words. Six-phase drives, induction machines, power quality.

\section{Introduction}

Since the re-emergence of multiphase machines and drives at the beginning of the 21th century, the efforts in the research community have been focused in the analysis of their advantages over the three-phase standard [1-5]. Apart from the well-known fault tolerant capability [6-10], some other innovative uses of the additional degrees of freedom have appeared in recent times [11-13].

Among the different types of multiphase machines, those with multiple three-phase windings have found lower entry barrier at industry because they recycle to a large extent the well-proved three-phase technology [14-17]. Six-phase machines are among this type of $3 k$-phase systems. Opposite to the case of five- or seven-phase machines where the construction is always symmetrical, in the case of six-phase machines there are different types of configurations according to the spatial shifting of the three-phase windings. When this angle is $0^{\circ}$ the two sets of three-phase windings are in phase and the machine is termed double three-phase machine (D3). Nevertheless, the most popular configurations are the symmetrical type (S6) and the asymmetrical type with a spatial displacement of $30^{\circ}$ (A6) [18]. In addition the three kind of machines can be configured either with single or two neutrals points [6].

The aim in all cases is to generate a rotating MMF in order to drive the machine smoothly, but the spatial shifting of the windings has an impact on the currents that are needed to create the revolving flux. Certain spatial angles may lead to current harmonic cancellation that results in an improve power quality for the same torque/flux in the machine. Although the THD of specific six-phase machines has been calculated in literature, a comparative analysis of the power quality for the D3, A6 and S6 machines at different operating conditions is still missing. This works aims to fill this gap and provide a comprehensive analysis of the current distortion as a function of the spatial angle between windings.

The paper is structured so that the basics about six-phase machines are reviewed in section 2, the field oriented control and power quality indices are described in section 3 , the simulation results are presented in section 4 and the main conclusions are lastly summarized.

\section{Six-phase induction motor drives. Generalities.}

The six-phase induction motor drive under consideration consists of a six-phase machine supplied from two threephase two-level voltage source converters (VSCs) that are connected to a single dc-link. The machine has two sets of three-phase windings and the spatial shifting between the set 1 and 2 of windings is termed $\gamma$ in what follows. When $\gamma=0^{\circ}, 30^{\circ}$ and $60^{\circ}$ the double three-phase (D3), asymmetrical six-phase (A6) and symmetrical sixphase (S6) machines are obtained, respectively. 
D3

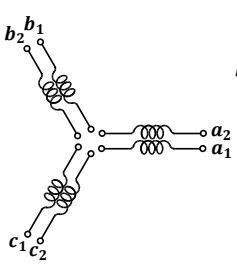

(a) $\gamma=0^{\circ}$
A6

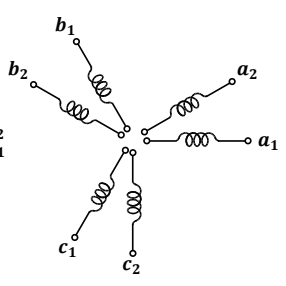

(b) $\gamma=30^{\circ}$
56

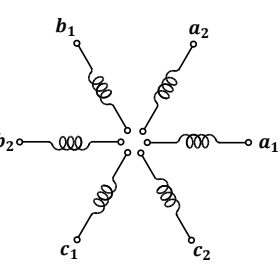

(c) $\gamma=60^{\circ}$
Fig. 1. Three mainstream six-phase machines: a) D3: Dual three-phase machine $\left(\gamma=0^{\circ}\right)$, b) A6: asymmetrical six-phase machine $\left(\gamma=30^{\circ}\right)$ and c) S6: symmetrical six-phase machines $\left(\gamma=60^{\circ}\right)$.

Fig. 1 schematically shows the three machines that will be considered in this work.

For control purposes six-phase machines are typically analyzed using the vector space decomposition (VSD) that results from the applications of the generalized Clarke transformation, which for the case of a six-phase machine with an arbitrary spatial shifting $\gamma$ can be expressed as:

$$
\begin{gathered}
{[T]=\frac{1}{\sqrt{3}}\left[\begin{array}{cccccc}
1 & \cos (\theta) & \cos (2 \theta) & \cos (\gamma) & \cos (\theta+\gamma) & \cos (2 \theta+\gamma) \\
0 & \sin (\theta) & \sin (2 \theta) & \sin (\gamma) & \sin (\theta+\gamma) & \sin (2 \theta+\gamma) \\
1 & \cos (2 \theta) & \cos (\theta) & -\cos (\gamma) & -\cos (\theta+\gamma) & -\cos (2 \theta+\gamma) \\
0 & \sin (2 \theta) & \sin (\theta) & \sin (\gamma) & \sin (\theta+\gamma) & \sin (2 \theta+\gamma) \\
1 & 1 & 1 & 0 & 0 & 0 \\
0 & 0 & 0 & 1 & 1 & 1
\end{array}\right]} \\
{\left[i_{\alpha s} i_{\beta s} i_{x s} i_{y s} i_{0+} i_{0-}\right]^{T}=[T] \cdot\left[i_{a 1} i_{b 1} i_{c 1} i_{a 2} i_{b 2} i_{c 2}\right]}
\end{gathered}
$$

where $\theta=2 \pi / 3$.

Applying the transformation (1) into the phase variable model of the six-phase machine with standard assumptions (sinusoidal MMF distribution, negligible iron losses and saturation), the model in VSD variables can be written as:

$$
\begin{gathered}
v_{\alpha s}=\left(R_{s}+L_{s} \frac{d}{d t}\right) i_{\alpha s}+M \frac{d}{d t} i_{\alpha r} \\
v_{\beta s}=\left(R_{s}+L_{s} \frac{d}{d t}\right) i_{\beta s}+M \frac{d}{d t} i_{\beta r} \\
v_{x s}=\left(R_{s}+L_{l s} \frac{d}{d t}\right) i_{x s} \\
v_{y s}=\left(R_{s}+L_{l s} \frac{d}{d t}\right) i_{y s} \\
0=\left(R_{r}+L_{r} \frac{d}{d t}\right) i_{\alpha r}+\omega_{r} L_{r} i_{\beta r}+M \frac{d}{d t} i_{\alpha s}+\omega_{r} M i_{\beta s} \\
0=\left(R_{r}+L_{r} \frac{d}{d t}\right) i_{\beta r}-\omega_{r} L_{r} i_{\alpha r}+M \frac{d}{d t} i_{\beta s}-\omega_{r} M i_{\alpha s} \\
T_{e}=p M\left(i_{\beta r} i_{\alpha s}-i_{\alpha r} i_{\beta s}\right)
\end{gathered}
$$

Since the machine has distributed windings, the flux and torque production is confined to the $\alpha$ - $\beta$ plane, whereas $x-y$ currents are purely related to copper losses. The zero sequence components are omitted in (2) since this work only explores the case with two isolated neutrals, and consequently zero-sequence currents cannot flow. As it can be noted in (1), the phase currents can be reconstructed from $\alpha-\beta$ and $x-y$ currents, and this means that the THD of the phase currents will be formed by two currents of different nature. While the harmonics in the $\alpha-\beta$ subspace will result in additional torque ripple, the current harmonics in the $x-y$ subspace will only generate copper losses. This implies that for the same THD of the phase currents one machine can have high torque ripple and low copper losses or vice versa. This will be analysed in depth in section IV.

\section{Field oriented control (FOC) and power quality (PQ) of the six-phase induction motor drives.}

The six-phase induction machine (IM) considered in this work is regulated with a high-performance FOC. This control follows the cascaded approach used in threephase machines with an outer speed loop and inner current loops. The main difference is that four PI controllers need to be used due to the appearance of the $x-y$ current components. Fig. 2 depicts the scheme of the FOC for the six-phase IM drive where the $\alpha$ - $\beta$ currents have been rotated in synchronous direction (matrix [D] is the Park transformation that performs the frame rotation), whereas $x-y$ currents are anti-synchronously rotated as in [11]. The four current controllers provide the voltage references that are subsequently passed to the pulse width modulation (PWM) stage. This work uses a carried-based PWM (CB-PWM) that compares two signals, a carried signal and a modulation signal. In this system the carriers are triangular waveforms with no lag between them. The main parameter that affects the PQ is the switching frequency. Section IV will show the effect of the switching frequency in D3, A6 and S6. In order to quantify the $\mathrm{PQ}$, the following performance indicators are used:

- THD: non-sinusoidal periodic signals can be represented as the sum of a set of sinewaves (harmonics) whose frequency corresponds to a multiple of the fundamental frequency. The total harmonic distortion (THD) relates the harmonic content to the fundamental component. It provides a general indication of the quality of the PQ. This index is defined as the ratio of the RMS value (percentage) of total harmonic components and the fundamental component corresponding to the effective value:

$$
T H D_{1}(\%)=\frac{\sqrt{\sum_{2}^{\infty} I_{k}^{2}}}{I_{1}} \cdot 100 \%
$$

In this multiphase system, THD will be calculated for stator phase currents $\left(i_{a 1}, i_{b 1}, i_{c 1}, i_{a 2}, i_{b 2}, i_{c 2}\right)$ as well as for $\alpha-\beta$. While the former provides general information about the PQ and total harmonic losses, the latter is related to the harmonic distortion in torque and flux.

- Ripple: The ripple is a small unwanted residual periodic variation of the expected signal. For this 
study, the ripple of the $x-y$ currents will be obtained from the expression:

$$
\operatorname{Ripple}(A)=\sqrt{\sum\left(I_{k}\right)^{2}}
$$

This index will offer information about copper losses in the machine.

\section{Simulation results.}

This section provides extensive simulation results for the whole operating range of the six-phase drive shown in Fig. 1 and arbitrary values of the angle $\gamma$. The simulation has been performed in Matlab/Simulink with a fixed-step fundamental sampling time of $1 \mu \mathrm{s}$. The closed-loop FOC scheme shown in Fig. 2 is run in a loop that sweeps reference speeds from 500 to $1300 \mathrm{rpm}$ and load torque values from -2 to $-10 \mathrm{Nm}$. This procedure serves to evaluate the THD of the phase currents in the whole operating range. Even though the simulations have been carried out using value of $\gamma$ from $0^{\circ}$ to $60^{\circ}$ in steps of $10^{\circ}$, the results are summarized for the most usual configurations of $0^{\circ}, 30^{\circ}$ and $60^{\circ}$. Since the power quality is directly dependent on the switching frequency $f_{s}$, this value is also varied from $500 \mathrm{~Hz}$ to $10 \mathrm{kHz}$.

Fig. 3 shows the phase current THD for the whole operating range when the value of $\gamma$ is $60^{\circ}, 30^{\circ}$ and $0^{\circ}$. At a switching frequency of $500 \mathrm{~Hz}$ the resulting THD is similar for the three types of six-phase machines. As the speed is decreased the THD diminishes because the fundamental period of the phase currents $T_{m}$ is higher and this mitigates somehow the inconvenience of using a low switching frequency. In other words, the ratio $T_{m} / T_{s}$ increases and this favours the generation of the sinewaves with a lower harmonic content. The situation differs however as the switching frequency is increased. At high switching frequencies the ratio $T_{m} / T_{s}$ is already high regardless of the value of the fundamental period, so the positive effect in the low-speed region is not so remarkable. On the other hand, the lower is the speed the lower is the required phase voltage and this implies that low modulation indices will result. At a certain breaking point the positive effect of operating with lower values of $T_{m}$ equals the negative effect of operating with lower modulation indices and the resulting THD becomes a horizontal plane, as it happens mostly at $10 \mathrm{kHz}$ for $\gamma=0^{\circ}$ and $60^{\circ}$ in Fig. 3. After this breaking point the tendency is reversed and the THD increases in the low-speed region due to the dominant effect of the low modulation indices, as it is the case of $\gamma=30^{\circ}$ at $10 \mathrm{kHz}$ in Fig. 3. A mild dependency with the load torque can also be noticed, obtaining a higher THD at low load torque values. This is so because the higher is the torque the higher is the required phase voltage, so operating at high loading condition implies a higher modulation index that in turn benefits the power quality.

A comparison of the tendencies for the three types of machines is shown in Fig. 4. It can be observed that at 500 $\mathrm{Hz}$ the three machines behave similarly in the low speed

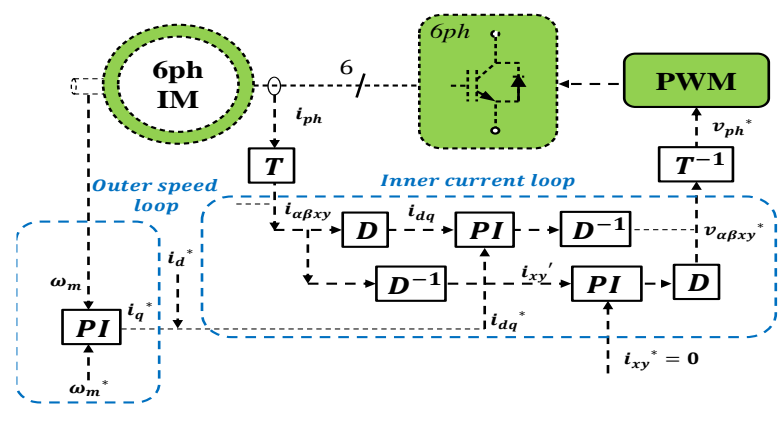

Fig. 2. Field oriented control (FOC) scheme of the six-phase IM drive.

region whereas at high speed the best machine is the double three-phase $\left(\gamma=0^{\circ}\right)$ and the worst machine is the symmetrical one $\left(\gamma=60^{\circ}\right)$. The differences in any case are around $10 \%$ at most. While the double three-phase machine remains the best as the switching frequency increases, the performance of the asymmetrical machine is deteriorated at high switching frequency, and the symmetrical six-phase machine becomes clearly better that the asymmetrical type in the low speed region.

While the three-phase machines phase currents are solely mapped into the $d-q$ plane, in six-phase machines the phase currents can be obtain both from $d-q$ and $x-y$ components. Since only the $d$ - $q$ subspace is involved in the energy conversion process, this means that it is important the way in which the THD of phase currents is split into the different planes. Aiming to distinguish between the ripple in both $d-q$ and $x-y$ planes, Figs. 5 and 6 show the THD of $\alpha-\beta$ currents and the ripple in the $x-y$ plane.

Curiously enough, Fig. 5 shows the double three-phase machine has the highest THD in the $\alpha-\beta$ plane for all switching frequencies. This is in contrast to what occurred in the THD of phase currents, and the explanation is that the $x-y$ ripple in double three-phase machine is zero, as shown in Fig. 6. Consequently it follows that the double three-phase machine will have the lowest losses (zero $x$ - $y$ currents) but the higher torque ripple (maximum $\alpha$ - $\beta$ current THD). As for the other two types of six-phase machines, the behaviour changes as the switching frequency increases. For low switching frequencies, the THD of the $\alpha-\beta$ currents is mostly similar for $\gamma=60^{\circ}$ and $30^{\circ}$ (Fig. 5), but the $x-y$ current ripple is clearly higher for the symmetrical machine (Fig. 6). For this reason the asymmetrical machine shows lower THD of the phase currents (Fig. 4). On the contrary, for high switching frequencies the THD of the $\alpha-\beta$ currents is higher in the symmetrical type in the low speed region (Fig. 5) whereas the $x-y$ current ripple dramatically increases for the asymmetrical machine. Since the increase of the $x-y$ current ripple is so much pronounced, the phase current THD was clearly deteriorated in the low speed region for the asymmetrical machine (Fig. 4). It can be concluded that at low switching frequencies both machines will have similar torque ripple and the asymmetrical type will have lower losses. Conversely, at high switching frequencies the symmetrical machine will have higher torque ripple but much lower losses. 

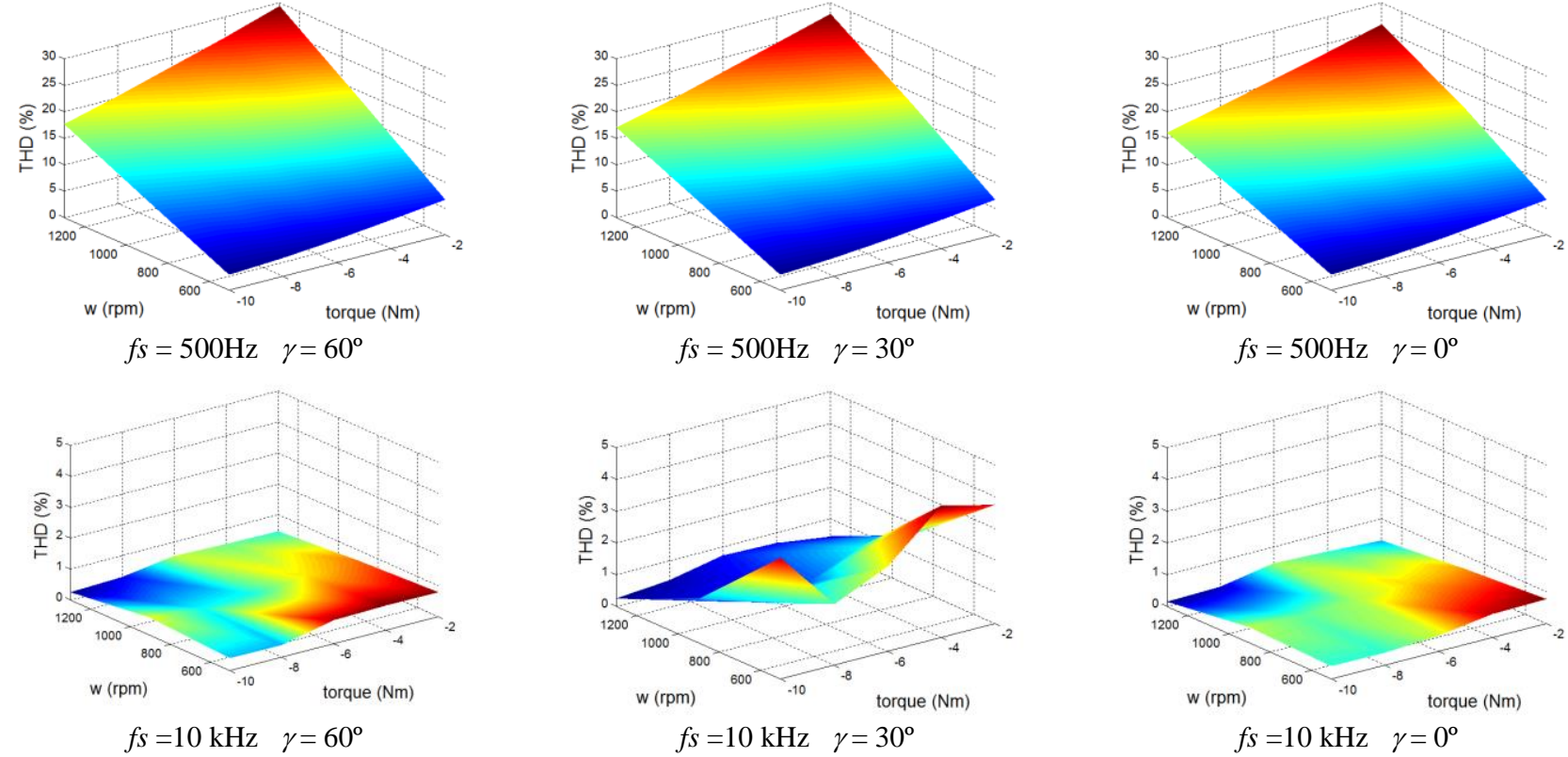

Fig. 3: THD for different speed and load torque values at switching frequencies of $500 \mathrm{~Hz}$ (top plots) and $10 \mathrm{kHz}$ (bottom plots) and three different angles $\gamma=60^{\circ}$ (left plots), $\gamma=30^{\circ}$ (middle plots) and $\gamma=0^{\circ}$ (right plots).
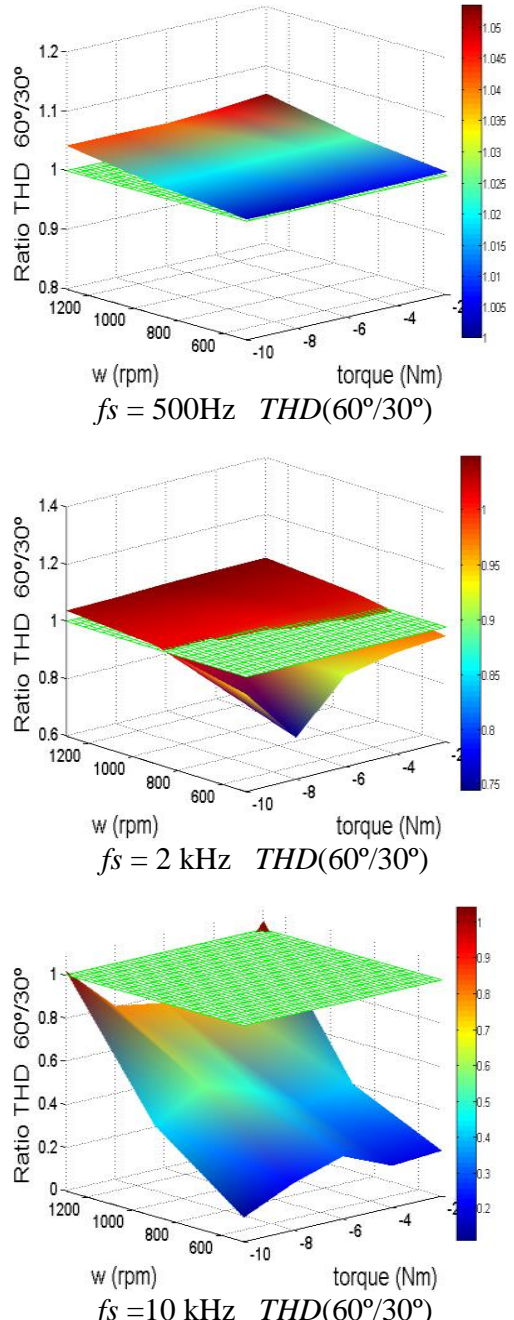
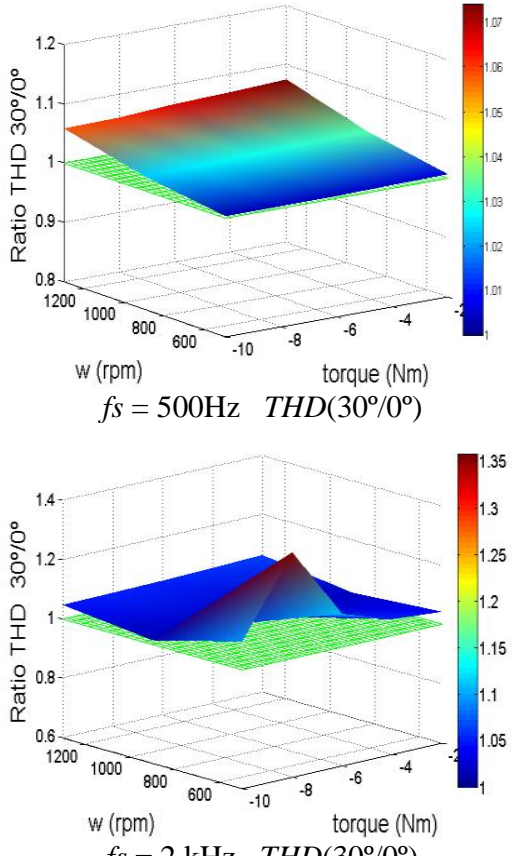

$f s=2 \mathrm{kHz} \operatorname{THD}\left(30^{\circ} / 0^{\circ}\right)$

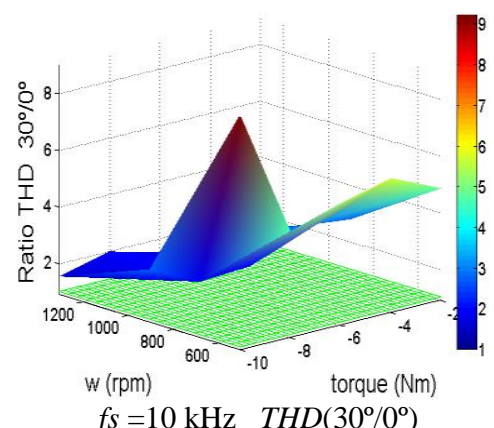

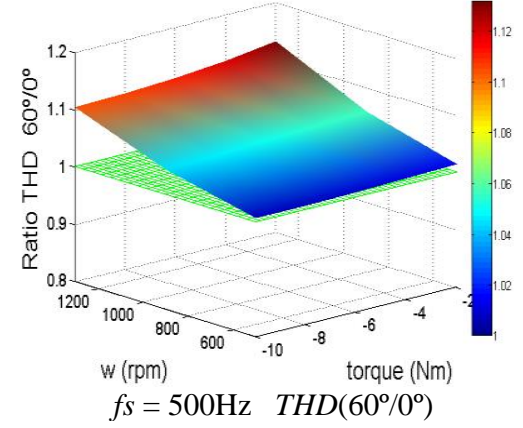

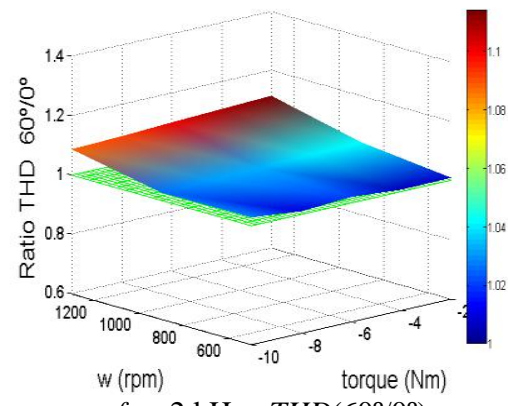

$f s=2 \mathrm{kHz} \quad \operatorname{THD}\left(60^{\circ} / 0^{\circ}\right)$

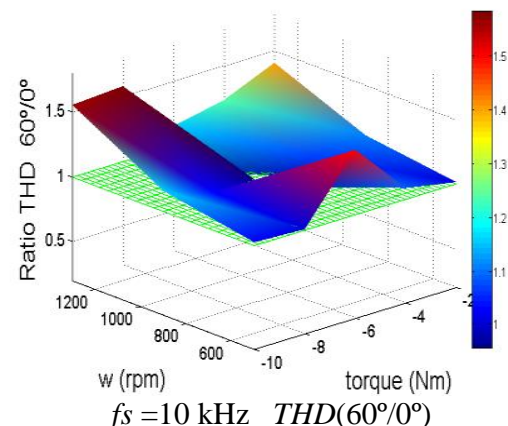

Fig. 4: Ratio of the THD of the phase currents for different speed and load torque values at switching frequencies of $500 \mathrm{~Hz}$ (top plots) $2 \mathrm{kHz}$ (middle plots) and $10 \mathrm{kHz}$ (bottom plots). The ratios are taken as $\operatorname{THD}\left(60^{\circ}\right) / \operatorname{THD}\left(30^{\circ}\right)$ (left plots), $\operatorname{THD}\left(30^{\circ}\right) / \operatorname{THD}\left(0^{\circ}\right)(\operatorname{middle}$ plots $)$ and $\operatorname{THD}\left(60^{\circ}\right) / \operatorname{THD}\left(0^{\circ}\right)$ (right plots). 

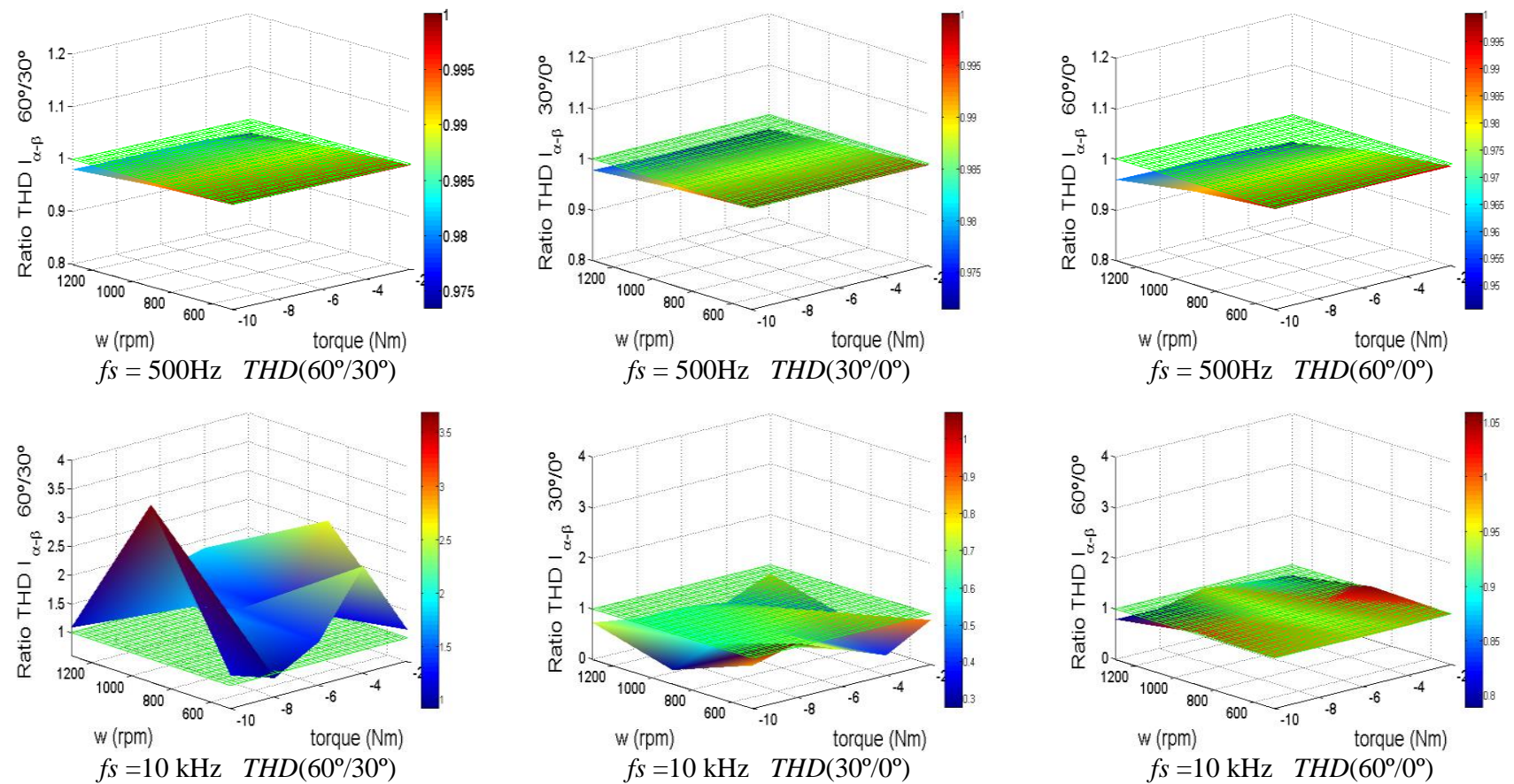

Fig. 5: Ratio of the THD of the $\alpha$ - $\beta$ currents for different speed and load torque values at switching frequencies of $500 \mathrm{~Hz}$ (top plots) and $10 \mathrm{kHz}$ (bottom plots). The ratios are taken as $\operatorname{THD}\left(60^{\circ}\right) / \operatorname{THD}\left(30^{\circ}\right)$ (left plots), $\operatorname{THD}\left(30^{\circ}\right) / \operatorname{THD}\left(0^{\circ}\right)$ (middle plots) and $\operatorname{THD}\left(60^{\circ}\right) / \operatorname{THD}\left(0^{\circ}\right)($ right plots).
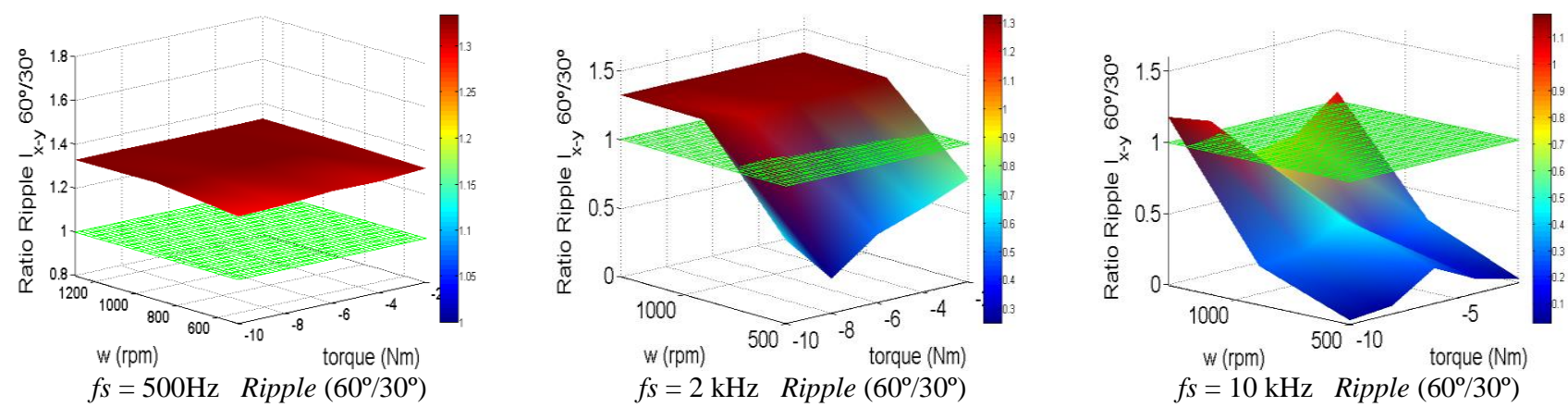

Fig. 6: Ratio $60^{\circ} / 30^{\circ}$ of the $x-y$ current ripple for different speed and load torque values at switching frequencies of $500 \mathrm{~Hz}$ (left plot), $2 \mathrm{kHz}$ (middle plot) and $10 \mathrm{kHz}$ (right plots).

\section{Conclusions.}

At low switching frequencies (e.g. $500 \mathrm{~Hz}$ ) the analysis reveals that the power quality is mostly similar for any value of the spatial shifting angle $\gamma$. The D3 provides minimum copper losses but slightly higher torque ripple whereas A6 presents lower losses than S6 but slightly higher torque ripple. At higher switching frequencies (e.g. $10 \mathrm{kHz}$ ) the lower THD of the phase currents is found for D3, but tis mainly caused by the null ripple of the $x-y$ currents. It has however the higher THD of the $\alpha-\beta$ currents and this implies the higher torque ripple. The A6 has the lower torque ripple among the three types of machines, but it is remarkable the high increase of the $x-y$ currents in the low speed region. This fact makes S6 to have lower THD of the phase currents than A6.

\section{Acknowledgement}

This work was supported by the Spanish Ministry of Science and Innovation under Project ENE2014-52536C2-1-R.

\section{References}

[1] E. Levi, R. Bojoi, F. Profumo, H.A. Toliyat and S. Williamson, "Multiphase induction motor drives - A technology status review," IET Electric Power Applications, vol. 1, no. 4, pp. 489-516, 2007.

[2] E. Levi, F. Barrero and M.J. Duran, "Multiphase machines and drives - Revisited," IEEE Trans. Ind. Electron., vol 63, no. 1, pp. 429-432, 2016.

[3] E. Levi, "Advances in converter control and innovative exploitation of additional degrees of freedom for multiphase machines," IEEE Trans. Ind. Electron., vol 63, no. 1, pp. 433448, 2016.

[4] F. Barrero and M.J. Duran, "Recent advances in the design, modeling and control of multiphase machines - Part 1," IEEE Trans. Ind. Electron., vol 63, no. 1, pp. 449-458, 2016. 
[5] M.J. Duran and F. Barrero, "Recent advances in the design, modeling and control of multiphase machines - Part 2," IEEE Trans. Ind. Electron., vol 63, no. 1, pp. 459-468, 2016.

[6] H.S. Che, M.J. Duran, E. Levi, M. Jones, W.P. Hew and N.A. Rahim, "Post-fault operation of an asymmetrical six-phase induction machine with single and two isolated neutral points," IEEE Trans. on Power Electronics, vol. 29, no. 10, pp. 54065416, 2014.

[7] I. Gonzalez-Prieto, M.J. Duran, F. Barrero, M. Bermudez and H. Guzman, "Impact of post-fault flux adaptation on sixphase induction motor drives with parallel converters," IEEE Trans. on Power Electronics, early access, DOI: 10.1109/TPEL.2016. 2533719, 2016.

[8] H. Guzman, M.J. Duran, F. Barrero, B. Bogado, I. GonzalezPrieto and M.R. Arahal, "Comparative study of predictive and resonant controllers in fault-tolerant five-phase induction motor drives," IEEE Trans. Ind. Electron., vol. 63, no. 1, pp. 606-617, 2016.
[9] H.S. Che, E. Levi, M. Jones, M.J. Duran, W.P. Hew, and N.A. Rahim, "Operation of a six-phase induction machine using series-connected machine-side converters," IEEE Trans. Ind. Electron., vol. 61, no. 1, pp. 164-176, 2014.

[10] I. Subotic, N. Bodo, E. Levi and M. Jones, "Onboard integrated battery charger for EVs using an asymmetrical ninePhase Machine," IEEE Trans. Ind. Electron., vol 62, no. 5, pp. 3285-3295, 2015.

[11] M.J. Duran, I. Gonzalez-Prieto, F. Barrero, M. Mengoni, L. Zarri and E. Levi, "A simple braking method for six-phase induction motor drives with diode front-end rectifier," Industrial Electronics Society, IECON 2015 - 41st Annual Conference of the IEEE, 9-12 Nov. 2015.

[12] S. Dwari and L. Parsa, "An optimal control technique for multiphase PM machines under open-circuit faults," IEEE Trans. Ind. Electron., vol. 55, no. 5, 2008 